\title{
MANIFESTAÇÕES PATOLÓGICAS NOS SISTEMAS ESTRUTURAIS EM AÇO DE EDIFICAÇÃO PÚBLICA: ESTUDO DE CASO NA UNIVERSIDAD DE SEVILLA (ESPANHA)
}

\author{
Juliana Furtado Arrobas Martins, Cesar Fabiano Fioriti
}

Universidade Estadual Paulista - UNESP, Departamento de Planejamento, Urbanismo e Ambiente, Presidente Prudente, SP. E-mail: juarrobas@hotmail.com. FAPESP

\section{RESUMO}

Este trabalho trata-se de um estudo de caso realizado na Universidad de Sevilla, Espanha, onde através de inspeção visual foram identificadas manifestações patológicas existentes nos sistemas estruturais em aço da Faculdade de Matemáticas pertencente a esta instituição. $O$ objetivo principal consistiu em detectar e exemplificar as manifestações patológicas ocorrentes nos sistemas estruturais em aço, apresentando seus aspectos gerais e realizando uma breve comparação com anomalias detectadas em edificações públicas semelhantes no Brasil. Para a realização deste trabalho partiu-se de um estudo bibliográfico acerca deste assunto, sendo realizadas, posteriormente, visitas de campo na edificação objeto de estudo, onde através de registro fotográfico detectaram-se as anomalias existentes, e com isso partiu-se para a descrição dos seus aspectos gerais e das causas prováveis. Com isso, este estudo anseia propiciar conhecimento e melhoras para a manutenção e vida útil das estruturas em aço.

Palavras-chave: Manifestações Patológicas, Aço, Edificação Pública, Degradação.

\section{PATHOLOGICAL MANIFESTATIONS IN STRUCTURAL SYSTEMS IN STEEL OF A PUBLIC BUILDING: CASE STUDY IN UNIVERSIDAD DE SEVILLA (SPAIN)}

\begin{abstract}
This work is a case study carried out at the Universdad de Sevilla, Spain, where through visual inspection were identified the existing pathological manifestations in the structural systems in steel in the Faculty of mathematics belonging to this institution. The objective was to detect and exemplify how pathological manifestations occurring in structural systems in steel, presenting the general aspects and performing a brief comparison with anomalies detected in similar public building in Brazil. For the achievement of this work was carried out a bibliographic study about this subject, performing then field visit where through photographic register was detected the existing anomalies and thus starting the description of general aspects and probable causes. Thus, this study yearn provide knowledge and improvements for maintenance and service life of steel structures.
\end{abstract}

Keywords: Pathologic manifestations, Steel, Public building, Deterioration. 


\section{INTRODUÇÃO}

Na construção civil a rapidez na execução e o emprego de novas tecnologias são fundamentais para tornar o mercado mais competitivo e possibilitar novos empreendimentos. Inovações e rapidez de execução acarretaram na necessidade de se desenvolver o conhecimento relacionado às estruturas e aos materiais, a fim de proporcionar o avanço das construções. Entretanto, ainda que o investimento em tecnologias relacionadas a essas construções cresceu e evoluiu desde o início das civilizações até os dias atuais, ainda assim, existem sérias limitações e inevitáveis falhas que acabam por prejudicar o desempenho de algumas estruturas.

Esses fatores conduzem ao surgimento de manifestações patológicas, que podem ser entendidas como a deterioração dos materiais que compõe o sistema estrutural, onde cada material reage de forma particular aos agentes externos e internos, sendo a velocidade de deterioração diferente um do outro (SOUZA e RIPPER, 1998).

Os problemas de deterioração da estrutura e de seus materiais componentes decorrem, em grande parte, de um projeto inadequado e de uma execução mal cuidada, deficiências que ainda se constata serem comuns, provocando a ocorrência de falhas que, fatalmente, resultam na necessidade de recuperação ou de reforço da estrutura (ou até mesmo, em casos extremos, de demolição) (SOUZA e RIPPER, 1998).

O uso do ferro e do aço está presente na história da humanidade desde a Antiguidade, passando a serem utilizados como materiais de construção a partir dos séculos XVIII e XIX e, juntamente com o desenvolvimento tecnológico que surgia, transformaram toda uma época através da Revolução Industrial (BANDEIRA, 2008).

No Brasil, a partir da segunda metade do século XIX, a burguesia emergente voltava-se para o consumo dos produtos europeus, e desta maneira, edifícios metálicos inteiros foram comprados, desde teatros, mercados, até estações ferroviárias (COSTA, 2001).

O controle de qualidade é de suma importância para garantir o melhor funcionamento das estruturas em aço, e, com isso, o fabricante deve garantir em todos os casos as características mecânicas e a composição química dos produtos fabricados, explicitando que cumprem todas as condições determinadas nas normas correspondentes, assim como garantir que os produtos não devem apresentem defeitos internos ou externos que afetem sua utilização (SEVILLA e ESPINOSA, 2003).

Hoje em dia se realiza um grande esforço para melhorar a qualidade da construção civil, porém, isso não diminui, por enquanto, a existência de uma preocupação significativa sobre o comportamento que as edificações atuais apresentarão no futuro. Não precisa ser muito 
pessimista para saber que muitas de nossas obras de hoje irão apresentar problemas dentro de poucos anos, e mais, muitas empresas com visão de futuro estão criando seus próprios departamentos dedicados ao estudo das manifestações patológicas com o objetivo de buscar soluções para estes problemas (CÁNOVAS, 1994).

A preparação técnica de arquitetos, engenheiros e construtores é o melhor caminho que se pode seguir para minimizar os defeitos e falhas na construção civil. Uma boa preparação técnica unida a um bom controle de qualidade de todas as fases de uma obra reduzirá de forma notável o numero de danos nas construções.

Com isso, este trabalho trata-se de um estudo de caso realizado em uma edificação pública pertencente à Universidad de Sevilla , Espanha, onde através de inspeção visual foram identificadas e analisadas as manifestações patológicas existentes nos sistemas estruturais em aço da edificação.

\section{METODOLOGIA}

O método escolhido para a formulação do trabalho foi o de estudo de caso, e conforme as etapas utilizadas no desenvolvimento deste trabalho foi possível percorrer um caminho curto e simplificado, visto que não foram utilizadas etapas de exames adicionais, mesmo porque não foi objetivo deste trabalho realizar exames laboratoriais sobre as propriedades físicas e químicas dos materiais constituintes do estudo de caso. Assim seguem as seis etapas utilizadas:

- 1a etapa: Estudo bibliográfico acerca do assunto a fim de proporcionar conhecimento e melhor entendimento sobre as manifestações patológicas que ocorrem em estruturas metálicas.

- 2a etapa: realização de visitas in loco na edificação pertencente à Universidad de Sevilla, para identificação e registro fotográfico das manifestações patológicas existentes nos sistemas estruturais em aço;

- 3ạ etapa: descrição dos aspectos gerais e das causas prováveis das manifestações patológicas encontradas nos sistemas estruturais em aço;

- 4ạ etapa: análise das manifestações patológicas encontrada nos sistemas estruturais aço;

- 5a etapa: breve comparação com anomalias detectadas nos sistemas estruturais em aço de edificação semelhante estudada no Brasil.

- 6a etapa: conclusões.

Destaca-se que não foi objetivo deste trabalho entrar no mérito da qualificação e da atuação dos profissionais e empresas que participaram dos projetos e execução das obras 
analisadas, tendo como único foco o levantamento das manifestações patológicas que podem vir a ocorrer em sistemas estruturais em aço e a importância de evitá-las.

\section{RESULTADOS}

Este estudo de caso foi realizado na Universidad de Sevilla, Espanha, sendo esta uma instituição pública de grande importância para o meio acadêmico espanhol e que conta com vários campus distribuídos pela cidade de Sevilha. O critério de escolha do edifício analisados partiu do quesito estrutural, ou seja, a definição do aço como material constituinte do sistema estrutural e por ter suas estruturas aparentes, pois nestas condições seria possível identificar e analisar as eventuais manifestações patológicas.

A Faculdade de Matemáticas foi projetada por um dos mais importantes arquitetos espanhóis do século XX, sendo inaugurada no ano de 1972, tendo hoje seus 43 anos de idade. Sua forma foi definida com precisão e se baseou na necessidade de perfeição construtiva. 0 edifício se divide em duas partes independentes, cada qual estabelecendo sua própria ordem geométrica e construtiva. As passarelas internas do edifício (Figura 1a) cumprem a função de separar o ambiente público do ambiente privado das salas de aulas e seminários, conectando pátios internos com o restante do edifício.

Percebe-se nesta edificação uma autenticidade construtiva, sendo possível notar o cuidado tomado com toda a estrutura metálica utilizada (Figura 1b), mostrando que neste caso a função persiste sobre o ornamento. De tal maneira que se mostra como o arquiteto imprime a importância sobre os materiais utilizados, os quais são profundamente conhecidos para então imprimir toda a importância para cada elemento constituinte.

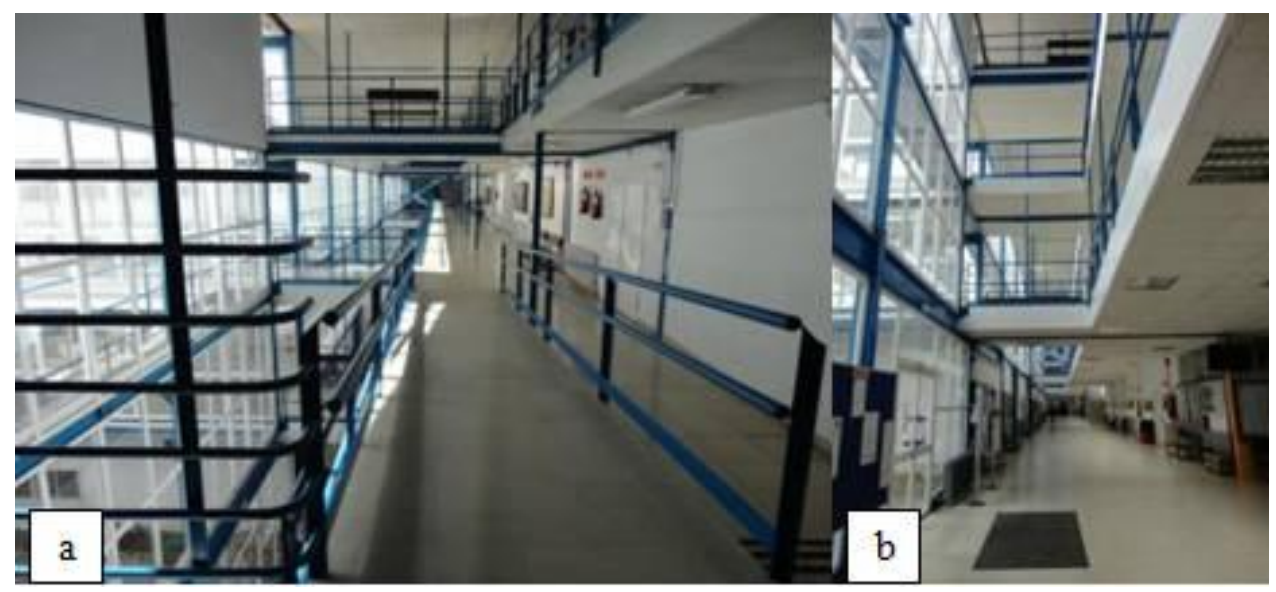

Figura 1. a) Passarelas internas; b) Estrutura metálica. 


\section{Aspectos gerais e causas prováveis das manifestações patológicas identificadas}

As manifestações patológicas mais relevantes identificadas na edificação analisada foram: corrosão nas bases dos pilares (Figura 2; Quadro 1), corrosão uniforme (Figura 3; Quadro 2), corrosão por pontos (Figura 4; Quadro 3) e soldagem deficiente (Figura 5; Quadro 4).

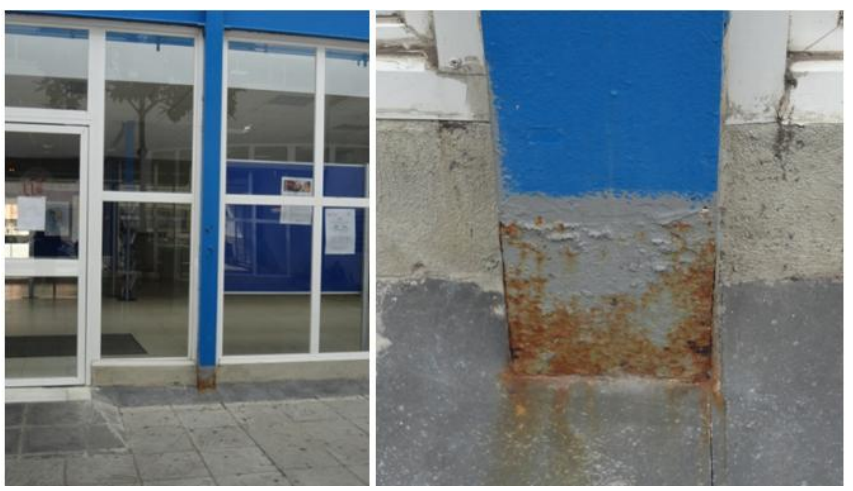

Figura 2. Corrosão nas bases de pilares distintos.

Quadro 1. Aspectos gerais e causas prováveis das bases dos pilares distintos.

\begin{tabular}{l|ll}
\hline \multicolumn{2}{c|}{ Aspectos gerais } & \multicolumn{1}{|c}{ Causas prováveis } \\
\hline •Base dos pilares no mesmo nível do & $\bullet$ Falha de projeto e/ou \\
piso; & $\begin{array}{l}\text { detalhamento; } \\
\text { •Perda de parte do acabamento }\end{array}$ & $\bullet$ Falta de manutenção; \\
(pintura); & $\bullet$ Excesso de umidade; \\
•Manchas marrom-avermelhadas & $\bullet$ Ação química da água; \\
devido ao processo existente de & $\bullet$ Elementos em contato com \\
corrosão na base. & águas residuais. \\
\hline
\end{tabular}
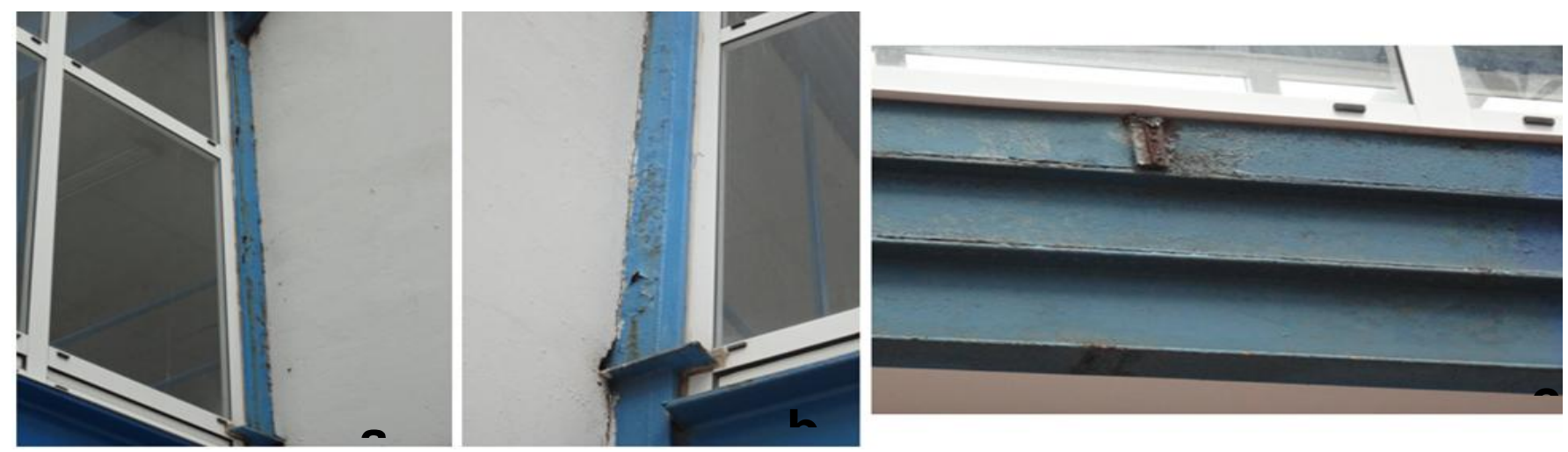

Figura 3. Corrosão uniforme 
Quadro 2. Aspectos gerais e causas prováveis da corrosão uniforme.

\begin{tabular}{|c|c|}
\hline erais & Ca \\
\hline $\begin{array}{l}\text {-Presença de corrosão uniforme; } \\
\text {-Perda de parte do acabamento } \\
\text { (pintura); } \\
\text {-Manchas marrom-avermelhadas } \\
\text { devido ao processo de corrosão } \\
\text { existentes nos perfis; } \\
\text { - Redução de massa dos perfis. }\end{array}$ & $\begin{array}{l}\text { •Falta de manutenção; } \\
\text { •Excesso de umidade; } \\
\text {-Ação química da água; } \\
\text {-Acúmulo de impurezas; } \\
\text {-Perda de material de } \\
\text { recobrimento e proteção (tinta). }\end{array}$ \\
\hline
\end{tabular}
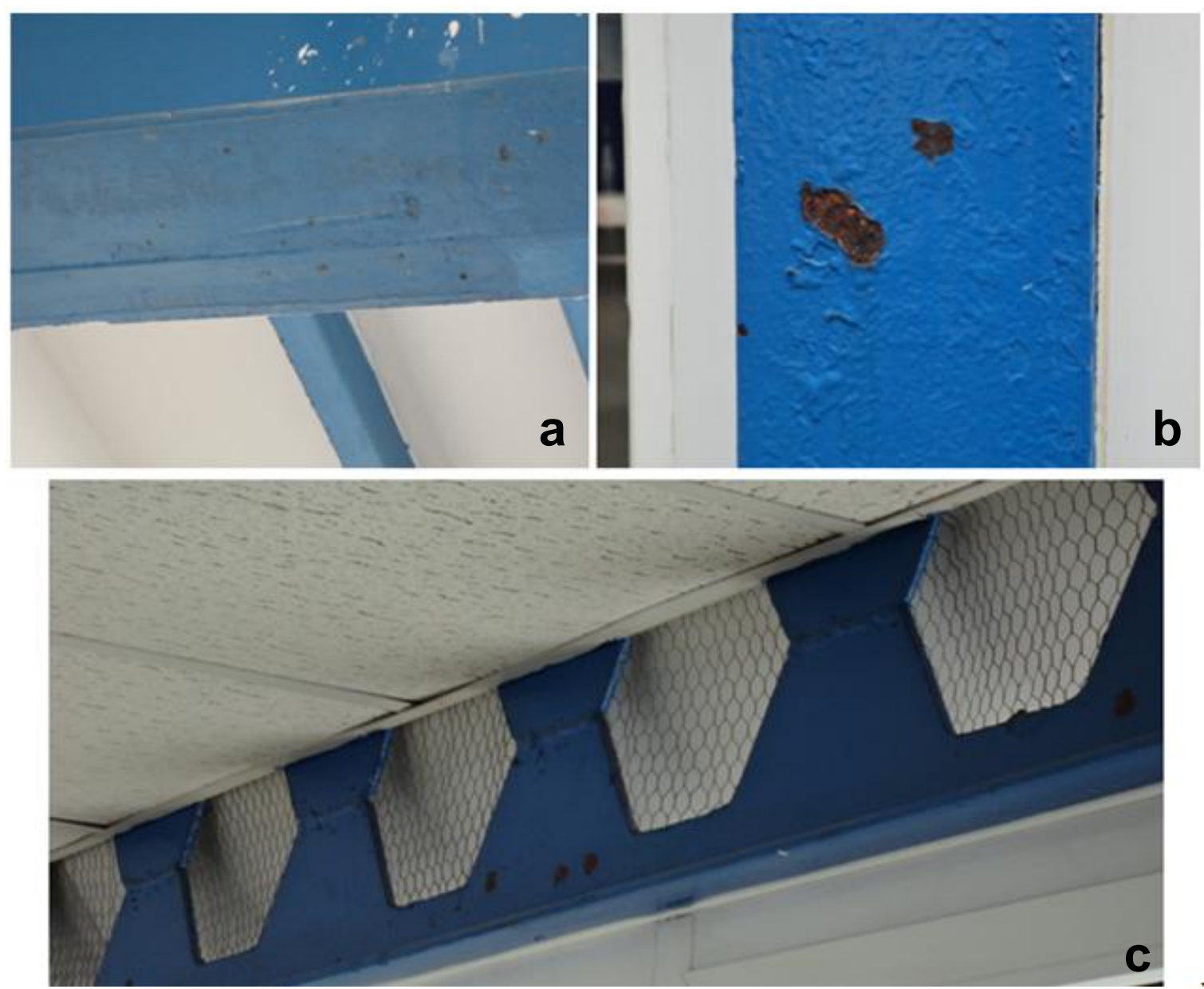

Figura 4. Corrosão por pontos. 
Quadro 3. Aspectos gerais e causas prováveis da corrosão por pontos.

\begin{tabular}{|c|c|}
\hline Aspectos gerais & Causas prováveis \\
\hline $\begin{array}{l}\text {-Presença de corrosão por pontos; } \\
\text {-Perda de parte do acabamento } \\
\text { (pintura); } \\
\text {-Manchas marrom-avermelhadas } \\
\text { devido ao processo de corrosão } \\
\text { existente nos perfis. }\end{array}$ & $\begin{array}{l}\text {-Excesso de umidade; } \\
\text {-Ação química da água; } \\
\text {-Acúmulo de impurezas; } \\
\text {-Perda do material de } \\
\text { recobrimento e proteção (tinta). }\end{array}$ \\
\hline
\end{tabular}
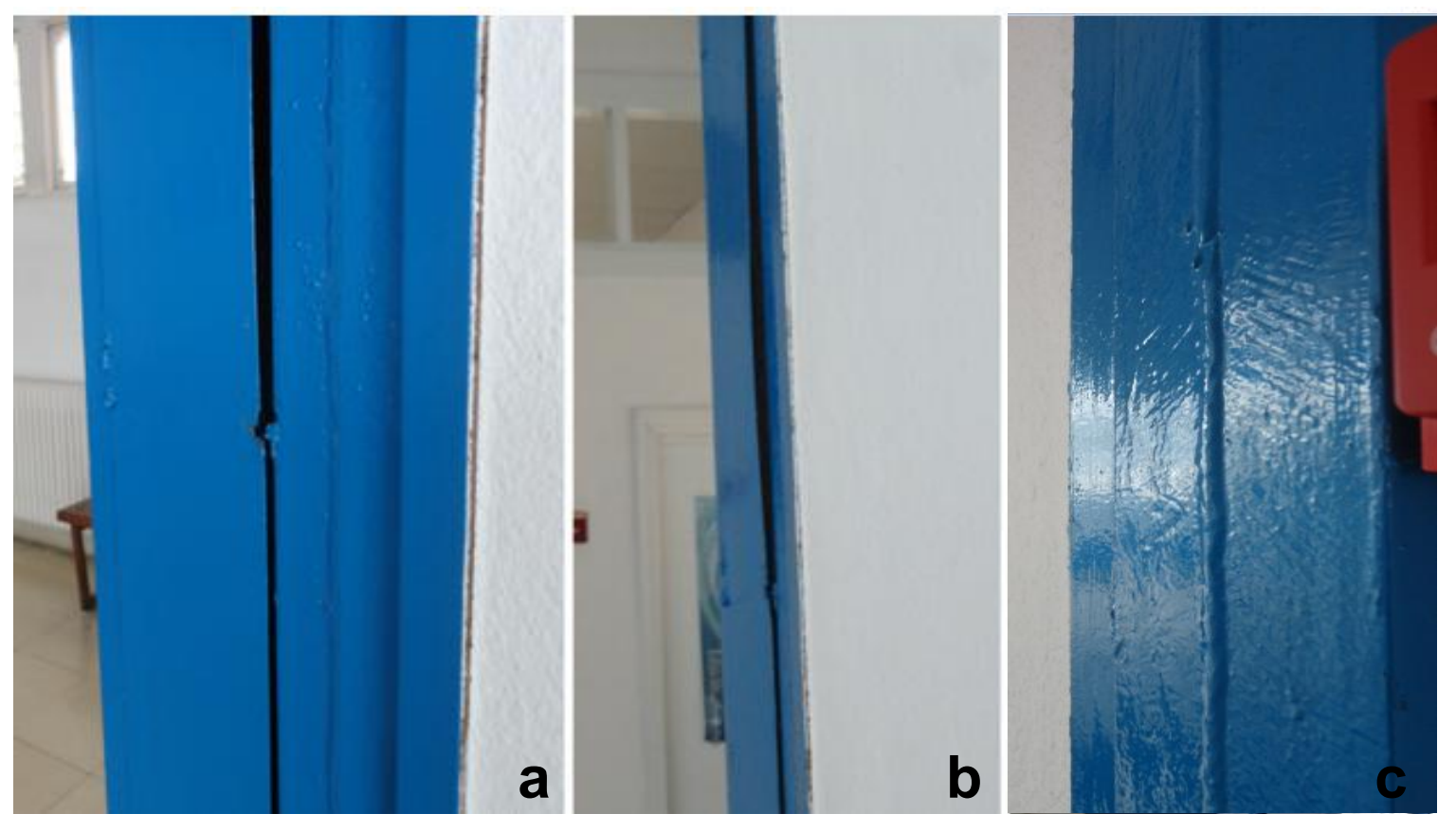

Figura 5. Soldagem deficiente.

Quadro 4. Aspectos gerais e causas prováveis das soldagens deficientes

\begin{tabular}{l|l}
\hline \multicolumn{1}{c|}{ Aspectos gerais } & \multicolumn{1}{c}{ Causas prováveis } \\
\hline •Rompimento da liga metálica & $\begin{array}{l}\text { •Porosidade: bolsas de gás ou } \\
\text { vácuo que ocorrem no local da } \\
\text { utilizada na soldagem; }\end{array}$ \\
•Liga metálica utilizada na soldagem; & •Fusão incompleta; \\
em alto relevo; & •Excesso de liga metálica; \\
•Aspecto de trabalho mal executado. & •Falha de execução. \\
\hline
\end{tabular}




\section{DISCUSSÃO}

Entre as manifestações patológicas detectadas na edificação analisada, a mais recorrente foi a corrosão uniforme que ocorreu em vários elementos da estrutura (tanto vigas quanto pilares) sendo uma anomalia que se consiste em uma camada visível de corrosão que se forma em quase que toda a extensão do perfil. É caracterizada pela perda de massa e diminuição da seção transversal da peça, podendo ocorrer principalmente devido ao contato com água, pó, ou devido a alguns agentes agressivos da própria atmosfera.

A corrosão também ocorreu por pontos e em mais de um elemento da estrutura. Diferentemente da corrosão uniforme, essa anomalia ocorre em forma de pontos que podem vir a ser altamente destrutivos, pois geram perfurações nas peças sem uma perda notável de massa e peso da estrutura, podendo provocar a ruptura do elemento.

A corrosão na base de pilar ocorreu de forma isolada e provavelmente por acúmulo de água e pó, devido ao fato do erro cometido de se deixar a base em contato direto com o piso, sendo que este pilar deveria estar sobre uma base de outro material mais resistente às ações da água, como o concreto por exemplo.

As soldagens deficientes foram detectadas nas ligações que unem os perfis que constituem os pilares e podem ter sido ocasionas devido a fatores como falta de detalhamento de projeto, falhas de execução ou ainda devido a uma mão de obra deficiente, chamando a atenção para a saliência existente, além de alguns pontos de fratura das soldas, prejudicando as uniões entre os elementos e podendo gerar anomalias mais sérias.

Depois de analisar as manifestações patológicas existentes nesta edificação pública estudada em Sevilha, Espanha, foi possível perceber que na totalidade não se detectou grandes quantidades de anomalias e as que ocorreram foram praticamente de forma isolada. As principais causas prováveis foram erros de projetos, erros de execução, uso de materiais de baixa qualidade e falta de manutenção. A partir da analise, foi possível perceber que a maioria dos problemas patológicos detectados foi causada por erros de projetos, que acabam gerando outros erros como os de montagem, por exemplo, que apareceram como a segunda causa mais provável. A qualidade dos materiais também deve ser discutida, pois a tinta utilizada para a pintura da edificação estudada apresentou problemas como bolhas e descascamento em vários elementos, tendo como principal causa a má qualidade deste material ou ainda a falta de manutenção.

Em relação às causas das anomalias detectadas, estas foram bastante semelhantes tanto para o estudo na Espanha como para um estudo semelhante realizado no Parque de Uso Múltiplo (PUM) na cidade de Presidente Prudente, Brasil, também estruturada em aço, sendo que em 
ambos os casos os erros de projeto estão como a principal causa da ocorrência de problemas patológicos, fato esse muito preocupante e alarmante quanto à qualidade dos profissionais das áreas da construção civil. Os erros de execução, a má qualidade dos materiais construtivos e a falta de manutenção também foram causas prováveis semelhantes para as anomalias analisadas durante os estudos nos dois países mencionados, sendo a principal diferença entre eles a quantidade de elementos danificados, em que na Espanha essa quantidade foi bastante inferior do que no Brasil.

\section{CONCLUSÃO}

Diferentes manifestações patológicas foram detectadas neste edifício estudado em Sevilla, na Espanha, assim como também em outros trabalhos semelhantes realizados no Brasil, o que acaba por evidenciar que esta é uma questão que afeta as estruturas de uma forma global e que necessita de maior atenção e cuidados.

$\mathrm{Na}$ edificação analisada, sua estrutura apresentou como problema patológico mais frequente a corrosão, sendo este um dano bastante comum em estruturas de aço devido às suas características como material, e mesmo assim ocorreram de forma isolada em um ou outro elemento, mostrando ser uma edificação bem projetada, executada e com materiais de boa qualidade.

Em vista disto, percebe-se que a quantidade de anomalias detectadas na edificação espanhola foi inferior às do Brasil, sendo este um indício de que em países desenvolvidos já existe uma maior preocupação com questões de qualidade, segurança e durabilidade dentro da construção civil, porém, destaca-se que ainda é necessária uma maior preocupação com as questões construtivas tanto na Espanha como no Brasil, e que mesmo que esse assunto esteja sendo cada vez mais estudado e difundido, mesmo assim muito ainda deve ser feito para melhorar as questões relacionadas aos problemas patológicos para que estes sejam menos frequentes e que não apresentem grandes prejuízos para a estrutura em sua totalidade, tendo como principal preocupação evitar os erros ainda comuns e garantir a vida útil das edificações.

\section{AGRADECIMENTOS}

A FAPESP - Fundação de Amparo a Pesquisa do Estado de São Paulo, pela concessão das bolsas de iniciação científica e de estágio de pesquisa no exterior à autora. 


\section{REFERÊNCIAS}

BANDEIRA. A. A. C. Análise do uso de estruturas de aço em edificações habitacionais de interesse social. Monografia - Especialização em Construção Civil Universidade Federal de Minas Gerais, Belo Horizonte, 2008. 122p.

CÁNOVAS, M. F. Patología y Terapéutica del hormigón armado. Tercera edición actualizada. 487p. Madrid, 1994.

COSTA, C. T. da. O sonho e a técnica: a arquitetura de ferro no Brasil. São Paulo: Editora da Universidade de São Paulo, 2001.

SEVILLA, J. B.; ESPINOSA, I. V. Materiales de construcción para arquitectos y arquitectos técnicos: Metales. 255p. Editora C.S.V., 2003.

SOUZA, V. C. M. de; RIPPER, T. Patologia, recuperação e reforço de estruturas de concreto. São Paulo: PINI, 1998. 